\title{
Urdimento
}

Revista de Estudos em Artes Cênicas E-ISSN: 2358.6958

\section{Tensões e interações entre dramaturgia e escritura dramática}

Clóvis Dias Massa

\section{Para citar este artigo:}

MASSA, Clóvis Dias. Tensões e interações entre dramaturgia e escritura dramática. Urdimento, Florianópolis, v. 1, n. 40, mar./abr. 2021.

do) DOI: http:/dx.doi.org/10.5965/1414573101402021e0209

Este artigo passou pelo Plagiarism Detection Software | iThenticate 
Tensões e interações entre dramaturgia e escritura dramática'

\title{
Resumo
}

Clóvis Dias Massa²

O estudo recupera algumas das principais definições de dramaturgia, compreendida como princípio que organiza a ação em função da cena, seja ela feita pelo autor dramático, encenador ou autor cênico, e visa compreender as relações que se estabelecem durante o processo dramatúrgico na elaboração da ação cênica, para além da noção dualista e arcaica que distingue texto dramático e encenação. Utiliza-se, para tanto, de casos do teatro de narração e do teatro de testemunho, ilustrativos do panorama das escrituras teatrais contemporâneas.

Palavras-chave: Dramaturgia. Escritura dramática. Ação cênica. Texto-material.

Tensions and interactions between dramaturgy and dramatic writing

\begin{abstract}
The study retrieves some of the main definitions of dramaturgy, understood as a principle that organizes the action according to the scene, whether performed by the dramatic author, director or scenic author, and aims to understand the relationships that are established during the process dramaturgical in the elaboration of the scenic action, beyond the dualistic and archaic notion that distinguishes dramatic text and staging. For this purpose, cases of narrative theater and witness theater, illustrative of the panorama of contemporary theatrical scriptures.
\end{abstract}

Keywords: Dramaturgy. Dramatic writing. Scenic action. Text-material.

Tensiones e interacciones entre dramaturgia y escritura dramática

\section{Resumen}

El estudio recupera algunas de las principales definiciones de dramaturgia, entendida como un principio que organiza la acción según la escena, sea ella realizada por el autor dramático, director o autor escénico, y tiene como objetivo comprender las relaciones que se establecen durante el proceso dramatúrgico en la elaboración de la acción escénica, más allá de la noción dualista y arcaica que distingue el texto dramático y la puesta en escena. Para ello, se utiliza de casos del teatro narrativo y del teatro testimonial, ilustrativos del panorama de las escrituras teatrales contemporáneas.

Palabras clave: Dramaturgia. Escritura dramática. Acción escénica. Texto-material.

${ }^{1}$ Esse artigo foi possível de ser escrito graças ao estágio realizado junto ao Groupe de Recherche Sur la Poétique de la Scène Contemporaine (IRET) na Université Sorbonne Nouvelle - Paris 3, com a supervisão do prof. dr. Joseph Danan, com bolsa de Pós-Doutorado no Exterior concedida pelo Conselho Nacional de Desenvolvimento Científico e Tecnológico - CNPq.

2 Professor Associado 4 na Universidade Federal do Rio Grande do Sul. Ministra disciplinas de Poéticas Teatrais, Teatro Comparado e Escrita Dramatúrgica. Integrante do PPGAC/UFRGS. Pesquisador no campo da história do teatro e da recepção teatral. clovisdmassa@gmail.com

(2) http://lattes.cnpq.br/6553962316361796 (D) http://orcid.org/0000-0002-1235-0011 
Termo que contém várias acepções, a dramaturgia ainda assim é vinculada de modo equivocado ao dramático e ao textual, talvez, devido à própria dificuldade de compreensão de uma atividade que reflete as transformações constantes da prática teatral.

É amplamente reconhecida a iniciativa de Gotthold Ephraim Lessing, no final do século XVIII, para a constituição de uma ciência e desenvolvimento da prática teatral na Alemanha. Em A Dramaturgia de Hamburgo, uma série de artigos escritos entre abril de 1767 e abril de 1768, Lessing não apenas expõe suas bases conceituais, ao propor uma teoria sobre a tragédia e a comédia, mas projeta o trabalho teórico na crítica e análise do acontecimento teatral, e dessa ciência emergente sobre a prática. Lessing considera as contribuições da arte teatral alemã no âmbito do repertório, atuação, música e espetáculo apresentadas por Johann Christoph Gottsched ${ }^{3}$ e Konrad Ekhof ${ }^{4}$, e defende que a teoria seja formulada "de tal modo que permita obtener resultados práticos nuevos, los que a su vez enriquecerán los planteamentos teóricos de partida. Su actividad como dramaturgista es el medio. Entiende las relaciones entre encena y sala como algo dinámico y vivo" (Hormigón, 2011, p. 17). A evolução do trabalho dramatúrgico, no papel da figura do dramaturg como conselheiro científico teatral vinculado à direção dos teatros se desenvolve a partir do século XVIII, assumindo uma diversidade grande de tarefas ligadas à formação do repertório, traduções e adaptações, colaboração com autores no processo de criação das obras e com diretores na realização dos espetáculos.

Desde então a concepção de dramaturgia evoluiu bastante em relação aos pressupostos em vigor naquela época. Consolidada na Alemanha, a função do dramaturg "sobre todo adquirió un lugar más definido, de mayor responsabilidad, dentro de las institucional teatrales y en el proceso de puesta en escena" (Hormigón, 2011, p. 30). Nesse sentido, são significativos os aportes de Erwin Piscator, desde o período em que trabalhou na Volksbühne, nos anos 1920, onde

${ }^{3}$ Catedrático de estética da Universidade Leipzig e colaborador da companhia de Carolina Nauber, Die Nauberin, entre 1727 e 1738.

${ }^{4}$ Ator, e diretor de cena. Fundador, em 1753, da Teatralische Akademie (Academia Teatral), na cidade de Schwerin. 
criou um departamento de dramaturgia, e de Bertolt Brecht, ele próprio responsável pela direção, adaptação do texto e concepção dramatúrgica (Braun, 1986) da montagem de A Vida de Eduardo II da Inglaterra, de Marlowe, no Kammerspiele de Munique, em 1923, sendo contratado como dramaturgista no ano seguinte pelo Deutscher Theater, sob a administração de Max Reinhardt. Brecht foi quem efetivamente potencializou o trabalho dramatúrgico, com o Berliner Ensemble equiparando sua função à de disciplinas como filosofia de práxis histórica, economia, sociologia e psicanálise. Essas ciências passaram a servir à dramaturgia como fonte de conhecimento, aprimorando sua técnica e sendo colocadas em diálogo para a compreensão de questões essencialmente dramatúrgicas, tais como a natureza dos conflitos, o significado das personagens e a complexidade dos processos sociais e individuais. Conforme Hormigón (2011, p. 34):

Las nociones de dramaturgia y trabajo dramatúrgico adquirieron gracias a ellas un nivel mucho más alto y unas responsabilidades y perspectivas inusitadas. Sus planteamientos impregnaron tanto el ámbito de la investigación y el análisis crítico como el de la práctica teatral. Después de la guerra y más concretamente en los años cincuenta, el concepto de dramaturgia se generalizó en Europa y la figura del dramaturgista proliferó en diferentes países.

Se considerarmos, como disse Bernard Dort em seu célebre artigo O Estado de Espírito Dramatúrgico (1986), que por dramaturgia não se deve ser entendida a atividade em si do dramaturgista, mas uma consciência, "um estado de espírito. Uma prática transversal”5 (1996, p. 10), continuaria válido seu sentido amplo, de superação "do estudo do texto dramático para englobar texto e realização cênica"6 (Pavis, 1999, p. 114), em que são projetadas as leis e elementos do drama e do teatro. Apesar de não ser recente, a noção de Dort, de que dramaturgia é "tudo o que se passa no texto e tudo o que se passa do texto ao palco", como disse num colóquio em 1985 (apud Danan, 2010a, p. 25) continua delimitando o campo histórico-conceitual da discussão.

\footnotetext{
${ }^{5}$ un état d'esprit, une pratique transversale. (Tradução nossa)

${ }^{6}$ Tradução de J. Guinsburg, Maria Lúcia Pereira e outros.
} 
Joseph Danan, em sua obra de referência sobre o tema, O que é a dramaturgia?, de 2010, esclarece os dois sentidos principais do termo: o primeiro, antigo, como "arte da composição de peças de teatro", que estaria do lado do texto; o segundo, moderno, associado à função de dramaturg, do "Pensamento da passagem para o palco das peças de teatro"7 (2010a, p. 12), do lado dessa passagem. Ao inverter o processo que vai da leitura do texto à sua representação, Dort inverteu os termos de leitura e pôs em primeiro plano a representação, o fato cênico que ainda não existe, mas que é transversalmente dramatúrgico, a ponto de não mais diferenciar dramaturgia e encenação, faces de uma mesma atividade. Essa imprecisão, em que o diretor se confunde com o dramaturgista, está expressa em A compra do cobre: conversas a quatro sobre uma nova forma de fazer teatro, de Brecht, texto escrito entre 1937 e 1951, em que os interlocutores são o ator, a atriz, o dramaturgista e o filósofo, e no qual a figura do diretor está ausente. Isso se torna ainda mais problemático em nossos dias, quando o paradigma de uma arte em dois momentos (Gouhier, 1989) é questionado, em um contexto em que o "teatro se sente tentado a expulsar o drama de sua esfera" (Dort apud Danan, 2010a, p. 9), no momento em que "ação se dilui e se desacredita ao ponto de parecer anular-se” (Dort apud Danan, 2010a, p. 9). A dramaturgia enquanto “organização da ação" remonta, desse modo, a uma prática produtora de sentido, algo que até os anos 1980 ainda era possível, mas que a crise do pensamento marxista e o chamado "fim das ideologias" determinam outro tipo de concepção. Quando o teatro se faz performance, instalação ou dança e se afasta do drama, no momento em que a mimese é colocada em questão e seu sentido é anulado, cogita-se o fim da dramaturgia.

Em artigo sobre esse tema, Danan observara que o teatro pós-dramático (Lehmann, 2007) explode e pulveriza a ação em micro-ações que não podem mais ser reconhecidas como fábula ou intriga. Naquele momento, ainda em 2006, ele lidava com a hipótese de que, ainda assim, a ação cênica estava "organizada ('ativada') não em função de um sentido, mas para produzir sentido, o qual me faz

7 Tradução de Luís Varela. 
pensar, ou ao menos, coloca em funcionamento meu pensamento"8 (2006, p. 50). Para tanto, Danan descarta a palavra sentido, que se apresenta incongruente para esse contexto, o que determinaria uma prática dramatúrgica ainda rígida, segundo os padrões de leitura provenientes do desenvolvimento das ciências humanas.

Em seu lugar, pressupõe algo tateante, conforme define Jean-Luc Nancy, algo que abre para o sentido ao invés de se encerrar nele, e que é anterior a qualquer significado porque os prevê "tanto quanto os torna possíveis"9 (apud Danan, 2010a, p. 49). A perda do domínio e do controle pelo sentido unívoco, se é que algum dia foi possível, determinou uma noção de dramaturgia enquanto prática disparadora do pensamento, como "alavanca" ou "trampolim" para o pensamento, tida então como "paradas, sinais, pontos de apoio na confusão do que está em movimento, referências para orientar a desordem de fluxos por um tempo."10 (Danan, 2010a, p. 51) Mesmo tendo avançado em sua definição, a ênfase no pensamento parece não dar conta da presença e da experiência partilhada próprias do pós-dramático (Lehmann, 2007, p. 143), que se afirma enquanto processo e manifestação, mais do que como resultado e significação.

Foi preciso mais tempo para que a crise de representação promovesse à dramaturgia e ao trabalho dramatúrgico na atualidade mais nitidez sobre a natureza de sua epistemologia. O processo de desdramatização que o teatro tem sofrido faz com que a dramaturgia traga em si "a chancela da própria negação"11 (Lehmann, 2007, p. 118), mas mesmo assim são oferecidos elementos de mimese ao espectador. A dramaturgia no tempo do pós-dramático, título de artigo específico de Danan sobre o assunto, expõe essa transformação profunda do teatro e da nossa relação com a cena: o estatuto da representação cede lugar à presentificação do performer, os seres que se apresentam diante do público não chegam a ser artistas e muito menos personagens, o que afeta o sentido de

\footnotetext{
${ }^{8}$ organisée ('activée') non en fonction d'un sens mais pour produire du sens, qui me fais penser, ou du moins, qui met en branle ma pensée. (Tradução nossa)

9 tout autant qu'ils les rend possibles. (Tradução nossa)

${ }^{10}$ Des arrêts, des signaux, des points de appui dans la confusion du mouvant, des repères pour orienter un temps le désordre des flux. (Tradução nossa)

11 Tradução de José Tonezzi.
} 
dramaturgia, visto que a dimensão mimética - que agora entra em colapso constituía a base do sentido. "O estado de espírito performativo se manifesta cada vez que a ação realmente concretizada na realidade do palco impõe sua necessidade e sua lei"12 (2013, pp. 72-73). De modo que, enfim, ao menos para Danan (2019, p. 18), resta à dramaturgia criar as condições da experiência.

A dramaturgia sendo "o que organiza a ação em função de uma cena" (Danan, 2010b, p. 120), seja ela o feito de um autor dramático ou de um diretor ou de um “autor cênico" determina, pela sua amplitude, que sua natureza é, por excelência, bastante expandida. A definição de que dramaturgia seria a circulação de energia que emana de três polos que se colocam em relação - ação, teatro e pensamento - (Danan, 2010b, p. 120) expressa sua natureza transversal. Apesar dos termos à primeira vista imóveis e determinantes, Danan enfatiza se tratar, respectivamente, de ação enquanto princípio ativo, um movimento; de uma cena, ao menos virtual, o que vale bem para as proposições de teatro tecnovivial que estamos vendo se difundir em tempos de pós-pandemia; e de um motor, algo que ponha em movimento e ordene as ações.

Cabe lembrar como a programação do Festival de Avignon, em 2005, rompeu com a tradição fundada por Jean Vilar, ao escolher Jan Fabre como estrela convidada, não apresentar um espetáculo de destaque no palco principal ou encenar alguma peça importante, o que ficou conhecido como a "querela do teatro": "Para mim, não há teatro sem narrativa, pois não pode haver pensamento se não há fábula", defendeu Olivier Py, convidado do festival na ocasião. "A ideia de que se possa separar o poema do teatro é a morte do teatro e o fim da civilização ocidental. Continuo a pensar que o teatro se faz a partir de um poema; se não, é circo"13 (apud Dupont, 2017, p. 14). Apesar de defesas conservadoras como essa, desde então se procurou afirmar a escritura que parte do palco, e até mesmo considerá-la como uma prática que não é nova. Conforme Romeo Castellucci

12 L'état d'esprit performatif se manifeste à chaque fois que l'action réellement accomplie sur la réalité du plateau impose sa nécessité et sa loi. (Tradução nossa)

${ }^{13}$ No original: Tradução de Joseane Pezotto e outros. 
afirma, em entrevista publicada no dossier de imprensa do Festival d'Avignon, em julho de 2008:

Não são as palavras que me interessam no teatro. As palavras pertencem ao reino da literatura. A natureza do teatro não é ser um ramo secundário da literatura. É a arte da carne, a arte mais próxima da vida, é a arte mais perigosa. Não existe relação perigosa com um livro ou com uma cidade, porque é uma relação individual que está em jogo. [...]. Entretanto, existe no meu teatro um trabalho imenso nos grandes arquivos das palavras, um trabalho de perfuração vertical, especialmente onde você não as ouve mais. Se o espectador não está mais ouvindo as palavras, é porque elas se tornaram eficazes"14 (Tackels, 2007, p. 19).

Como Jan Fabre, outros artistas aproximam os dois tempos da criação, como Joël Pommerat, Romeo Castellucci, Robert Lepage, François Tanguy, Angelica Liddel, Rodrigo García, entre outros. "Nesses autores, o texto (voluntariamente não dramático) é apenas um elemento (e uma hierarquia que pode variar) entre todos os que compõem a partitura cênica”15 (Danan, 2019, p. 20). Vinculados com frequência à escritura de palco (Tackels, 2015), em alguns casos de maneira até equivocada, esses artistas invertem o sentido e produzem dramaturgia a partir do palco. Seus textos são o que restou da apresentação, resíduos do acontecimento teatral.

Joël Pommerat e Rodrigo García, por exemplo, não se encaixam totalmente nessa modalidade, porque criam em constante vai-e-vem do texto e da cena. Pommerat aproxima o trabalho da escritura do texto com o trabalho de criação da encenação, pois considera que não escreve peças, escreve espetáculos (Pommerat, 2009, p. 14). Desse modo, se alimenta de improvisações, muitas vezes desencadeadas por textos escritos ou trazidos por ele, improvisações que depois podem ou não ser reelaboradas e reapresentadas aos atores, em diferentes estratos do texto que serão memorizados por eles "até que um dentre eles se

\footnotetext{
${ }^{14}$ Ce ne sont pas les mots qui m'intéressent au théâtre. Les mots appartiennent au domaine de la littérature. La nature du théâtre n'est pas d'être une branche secondaire de la littérature. C'est l'art de la chair, l'art le plus proche de la vie, c'est l'art le plus dangereux. Il n'y a pas de rapport dangereux avec un livre ou avec une ville, car c'est un rapport individuel qui est en jeu. [...]. Néamoins, il existe dans mon théâtre un travail immense sur les grandes archives des paroles, un travail de forage vertical surtout là où on ne les entend plus. Si le spectateur n'écoute plus les mots, c’est qu’ils sont devenus efficaces. (Tradução nossa)
}

15 Tradução de Clóvis Dias Massa. 
imponha e seja finalizado, após a criação da obra e as primeiras representações, na edição que o fixará”16 (Danan, 2018, pp. 34-35). García, também autor do texto que faz jorrar diretamente em cena, num mesmo gesto de criação, trata o texto "como um material entre outros"17 (Protar, 2017, p. 45), que deve ser pensado em jogo com os outros elementos do palco: atores, vídeos, alimentos, canções, figurinos. A relação com os corpos dos performers e com os materiais que emprega é comparável com a que tem um artista plástico com suas cores (Cornago, 2009), e a partir desses materiais organiza a sucessão de ações, como se comprova pelo uso de storyboards. Deste modo, ele propõe ações e imagens cênicas sem exatamente constituir uma linha de ação representada, deslocando, segundo Inés Stranger, o conflito em direção à relação espetáculo/público: “É evidente que, em todos os seus espetáculos, a relação texto/encenação é a expressão do conflito entre a pulsão do texto por criar uma ficção, e a vontade estética de García de organizar uma ação cênica que rompa essa ficção e que obriga o espectador a permanecer no presente da representação"18 (Stranger, 2007, p. 175), o que produz uma ação cênica real, física, biológica, inscrita dentro da tradição artística da performance.

Dissociada do texto dramático, a dramaturgia aporta dele elementos que se pode considerar análogos, mesmo com sua dessacralização. E, no entanto, uma das principais tensões entre dramaturgia e escritura dramática é que a defesa por essa desierarquização dos elementos se manifesta como sua desvalorização. Mais importante do que isso, é considerar o que muda nessa relação, quando um novo sentido de dramaturgia surge, então, para proporcionar jogos de sentido, para antecipar ou pressupor o que será a experiência, para pensar o futuro de uma ação cênica que, colocada em movimento, se realiza enquanto escritura atravessada pelo texto e pela encenação que são elaborados ao mesmo tempo.

\footnotetext{
16 jusqu'à ce que l'une d'entre elles s'impose et aboutisse, après la création de l'œuvre et les premières représentations, à l'édition qui le fixera. (Tradução nossa)

${ }^{17}$ comme un matériau parmi d'autres. (Tradução nossa)

18 Il est évident que, dans tous ces spectacles, la relation texte/mise en scène est l'expression du conflit entre la pulsion du texte pour créer une fiction, et la volonté esthétique de García d'organiser une action scénique qui brise cette fiction et qui oblige le spectateur à rester dans le présent de la représentation. (Tradução nossa)
} 
No caso de Pommerat, do trabalho dramatúrgico feito por Marion Boudier, a dramaturgia prospectiva não deixa de lidar com fontes textuais. Espécie "de investigação levada a serviço do autor-encenador e de seus atores ao longo do processo de criação"19 (Boudier, 2019, p. 33), essa dramaturgia prospecta o que ainda não existe, mas conduz o processo a partir da delimitação e da coleta da matéria documental pertinente ao tema abordado, com a definição de uma metodologia de trabalho e o acompanhamento das diversas evoluções cênicas feitas no processo de criação. Com esse tratamento, a dramaturgia não parece ficar apenas circunscrita ao invisível, como diria Pais (2004), numa atividade que estrutura os sentidos da composição visível da encenação "através das relações de cumplicidade entre os materiais cênicos no momento e no lugar da representação" (Boudier, 2019, , p. 94), no encontro de saberes e materiais efetuados no processo criativo, de partilha entre o encenador (ou coreógrafo), o elenco (ou grupo de bailarinas e bailarinos), o cenógrafo, o músico, o designer de luz, o figurinista e o dramaturgista, no espaço periférico de uma experiência conjunta que se dá com a participação do público. Se, na atualidade, o estatuto do texto na encenação teatral difere do que até então se considerava como tradicional, por vezes com o texto de partida se fazendo jazida "de onde vão ser extraídos os materiais, visuais, sonoros, corporais, coreográficos, espaciais do espetáculo" (Danan, 2018, p. 28), a escolha desse material utilizado "no trabalho de elaboração do espetáculo, especialmente no trabalho de improvisação a partir dele" (Danan, 2018, p. 29), o qual Danan denomina de material-jazida, não apenas ocorrem pari passu com a elaboração da encenação (enquanto atividade paralela e, por vezes, simultânea a essa), mas contribuem para a sua criação de sua dramaturgia.

Certo que Pais (2004) considera que as categorias visível e invisível não se opõem ou excluem mutuamente e que, ao contrário, implicam-se reciprocamente, havendo entre a encenação e a dramaturgia uma cumplicidade, sendo própria da dramaturgia estabelecer cumplicidades entre a concepção e a concretização do espetáculo. E, ainda que não seja facilmente reconhecida como componente

19 Tradução de Clóvis D. Massa. 
possível de ser identificada no espetáculo, já que, segundo a autora, a dramaturgia não encontra no paradigma da visão um espaço de existência autônomo, "o discurso dramatúrgico, posto que estabelece as relações de sentido do espetáculo, é o discurso dos elementos estruturados (2004, p. 84). Ao sustentar que é através da invisibilidade da dramaturgia que o espetáculo é constituído, habitando as margens do visível, Pais conclui que o discurso performativo é também um discurso dramatúrgico. Ele o estrutura através de relações de cumplicidade entre os materiais cênicos, das relações de sentido no tempo em que o espetáculo é visto/ouvido/percebido pelo público.

Em trabalho anterior sobre a teatralidade, definimos dramaturgia como sendo "toda e qualquer manifestação de tensões ou forças em situação de cooperação entre o ator-performer e o espectador, em forma de ação representada, falada ou presentificada” (Massa, 2017, p. 71-72), para enfatizar o papel da recepção nesse fenômeno. Esse viés tinha a finalidade de constituição de uma dramaturgia do espectador, fundamentada na ação cênica, mas lhe faltavam pressupostos de materialidade à proposição. Diante do que foi exposto até agora, sua projeção na escritura dramática (ou teatral, afinal onde termina uma e começa a outra?) promoveria um desvio a fim de superar a ideia de que à dramaturgia, sendo a dimensão invisível da encenação, referente ao seu sentido, restaria apenas o escondido e o que não está explícito, deixando à materialidade da encenação sua dimensão visível, como dramaturgia em ato. O reconhecimento da natureza da enunciação dramatúrgica deveria fazer com que os dramaturgos assumissem os elos existentes entre a palavra e a plasticidade da escritura teatral sem o temor de serem taxados de texto-centristas (Pavis, 2017, p. 97). Danan propõe um modelo de dramaturgia formado por um enquadramento duplo (dramaturgia no sentido 1 e no sentido 2), sendo dramaturgia esse dispositivo "proposto para produzir jogo e efeitos de sentido, sem que eu busque controlar nem um nem outro" (2010b, p. 121), mas com o risco do sentido que aí se produza transbordar do quadro. Nessas bases, podemos entendê-la, a dramaturgia, como dispositivo que fundamenta e engendra a escritura dramática, cênica ou performativa. 
A articulação de uma ação cênica pelo ator-performer de maneira representada, falada, presentificada, na qual se manifestam forças e tensões, surge na interação com o texto-material (Danan, 2010a, p. 37), ou seja, com textos que recusam o modelo da representação e que fogem da categoria do dramático, mesmo na origem tendo sido escritos para o teatro. O uso do texto-material, categoria que também abrange os textos não escritos para o teatro, desafia o trabalho dramatúrgico em seu sentido 2, partindo da coleta de documentos, da produção de testemunhos ou da seleção de textos filosóficos, históricos ou sociológicos, porque se pode com ele fazer qualquer coisa. O texto, assim considerado como material e não como drama, "alimenta o trabalho de cena de onde resultará a partitura" (Danan, 2018, p. 30), a qual tomará estatura dos textos dialógicos, bastante próxima dos textos dramáticos, e guardará traços de todo o processo.

Como você aborda o trabalho com os atores de Uma noite árabe [de Roland Schimmelpfennig]?

Claudia Stavisky: Em O Dragão Dourado [outra peça do mesmo autor], os cinco atores devem demonstrar virtuosismo e polimorfismo ao interpretar 15 personagens. Em Uma Noite Árabe, os atores podem penetrar no interior de um único personagem e o expor na trajetória da narrativa. Deste ponto de vista, o desempenho do papel é mais fácil de abordar, mas a partitura não é menos complexa. Os saltos permanentes na temporalidade e a dualidade de uma linguagem interna e externa impedem os atores de se envolverem em um jogo psicológico. A dificuldade é também a de uma partitura de uma precisão absoluta que toca em todos os registros. [...] Eles têm que encontrar o ritmo certo para essa partitura musical para vozes, desejos e velocidades com suas fugas e variações ${ }^{20}$ (apud Sermon \& Chapuis, 2016, p. 53).

${ }^{20}$ Comment abordez-vous le travail avec les comédiens dans Une nuit arabe [de Roland Schimmelpfennig]? Claudia Stavisky: Dans Le Dragon d'or [autre pièce du même auteur], les cinq acteurs doivent faire preuve de virtuosité et de polymorphisme en interprétant 15 personnages. Dans Une nuit arabe, les comédiens peuvent se couler à l'intérieur d'un seul et même personnage et le déployer dans la trajectoire du récit. De ce point de vue, la prise de rôle est plus simple à aborder, mais la partition n'en est pas moins complexe. Les sauts permanents de temporalité et la dualité d'une langue intérieure et extérieure empêchent les comédiens de se prendre dans un jeu psychologique. La difficulté est aussi d'une partition d'une précision absolue qui joue sur tous les registres. [...] Il leur faut trouver le rythme juste de cette partition musicale pour voix, désir et courses de vitesse avec ses fuites et ses variations." (Tradução nossa) In: "Entretien avec Claudia Stavisky à propos du Dragon d'or / Une nuit arabe, de Roland Schimmelpfennig”, Le Journal du NTA. Nouveau Théâtre d'Angers - Centre dramatique national Pays de la Loire, no 7, automne-hiver, 2011, p. 18. Disponível em : «www.nta-angers.fr/IMG/pdf/Journal7_NTA.pdf ». 
Portanto, essa escolha determina ao jogo com o texto a ampliação das relações, faz com que ele adquira sentidos pelos "ritmos e sonoridades da linguagem, orquestração das vozes, dos registros, das velocidades e dos movimentos da palavra"21 (apud Sermon \& Chapuis, 2016, p. 54). O palco se torna, nesse caso, o local onde se coloca à prova esse material. No entanto, o que teria efetivamente mudado entre o "teatro narrativo" 22 proposto por Antoine Vitez ${ }^{23}$, no qual a narrativa não é adaptada para uma peça de teatro, distancia-se do dramático mas guarda seu estatuto de texto, fórmula essa que é seguida pelo diretor francês Didier Bezace, quem considera que é parte de seu trabalho "procurar soluções dramatúrgicas para que a ação exista"24 (Danan, p. 50), e práticas mais recentes como as de Joris Lacoste, da Encyclopédie de la Parole? Lacoste se utiliza do registro sonoro real, como no espetáculo para crianças e adolescentes Blablabla, em que a performer reproduz em sampler os áudios manipulando um aparelho digital que contém registros de falas, documentos orais coletados nas ruas ou em espaços internos. Em sua série Suíte nำ1, nํ2, nํ3, etc., os integrantes demonstram a virtuose vocal, falando ou mesmo cantando, como ocorre com o casal de cantores líricos acompanhado por um pianista em Suíte no 3. Com materiais tão díspares quanto a fala de incentivo de um treinador de time de futebol no intervalo da partida ou um discurso no parlamento grego diante da grave crise econômica que se instaurou, o conteúdo dos textos nos diz algo, porém também nos fala por sua linguagem e, principalmente, pelo modo de sua utilização no espetáculo. Propostas como essas repercutem o efeito da mídia e do digital (Pavis, p. 98), dispensam a linearidade do relato, embaralham os fios narrativos e encontram - através da maneira de contar algo, da dramatização da linguagem, numa espécie de pulsão rapsódica (Sarrazac, 2017) - os procedimentos para a sofisticação da escritura teatral.

\footnotetext{
${ }^{21}$ rythmes et aux sonorités du langage, orchestration des voix, des registres, des vitesses et des mouvements de la parole. (Tradução nossa)

22 Em francês, "théâtre-récit."

${ }^{23}$ Que no Brasil encontra um exemplo dessa variante com o 'romance-em-cena' de Aderbal Freire Filho.

${ }^{24}$ chercher des solutions dramaturgiques pour que l'action existe. (Tradução nossa)
} 
Figuras 1 e 2 - Trecho do texto M.A.M.A.E.:

Meurtre - Artistique - Munitions - Action - Explosion, de Nadège Prugnard

une fille battue une bohémienne une de l'ADASS Alcool Dépression Angoisse Suicide Suicide

Spiroktazine

Lercadipine

Captoprine

Odrickine

Cibarexine

Catpressine

Reniticine

Pritorine

Altzidane

Barbiturique

Félodipine

\section{Lascate}

\section{Lascate me Morire}

J'suis orpheline ma mère est morte j'avais 6 ans mon père l'a tué et puis s'est tué coup de carabine balle dans la bouche les taches de sang sur le papier vert une balle de sang la langue du chien qui lèche le sang sur le papier vert je l'ai étranglé p'tit enculé j'aime pas les chiens faut tous les tuer

$$
\text { F4 }
$$

Chiwawa

Caniches

Pitbulls

Chien de

Traîneau Nains

de Jardin

j'les noie

dans

l'berceau

tête dans le

formol avec

des pierres

dessous

la terre

une flaque de

sang je les

enterre à
F1

NO DOGS

F2

FIXDOGS

FIX DOGS

NO DOGS

NO FIX DOGS

NO DOGS

NO

NO

DOGS

TOGETHER

SUICIDE

TOGETHER

SUICIDE
TIRE

TIRE

TUE

TIRE

FLINGUE

TIRE

TUE

TIRE

TIRE

TIRE

TUE
F5 looooooost

F2 TIRE PUTAIN MAIS TIRE

F5 F3

Je suis une fleur

Je respire dans la

fraîcheur

Je suis une fleur

Je suis

une jonquille

Je suis fraîche

Je suis quille

Est-ce que quelqu'un

Looooooost

menthe? 


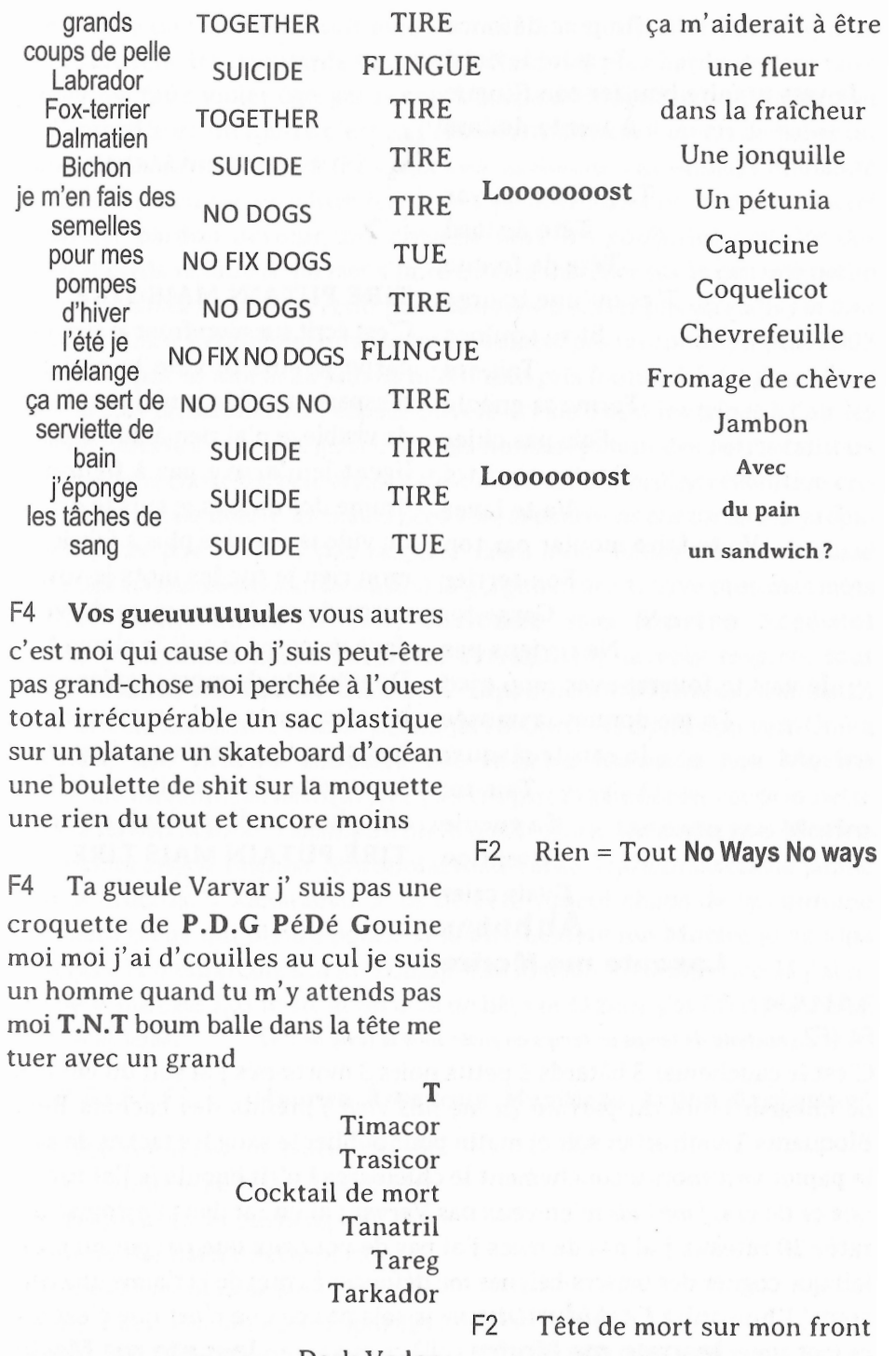

Ta gueule Varvar

Fonte: Reprodução de Al Dante \& l'auteure

A título de referência, dentro do panorama das escrituras da atualidade, os textos de Nadège Prugnard, diretora da Magma Performing Théâtre - elaborados no contexto de colaboração com outros coletivos ou companhias para as artes da rua, a arte da performance e a cena rock - trazem a marca do afastamento da escritura tradicional. Sua publicação mantém a indefinição da sequência ou da 
ordem do tempo das falas, como em M.A.M.A.E. Meurtre - Artistique - Munitions Action - Explosion. Aperçu des attaques suicides perpetrées par des artistes. ${ }^{25}$ (Figuras 1 e 2), em que a autora torna audível as palavras sufocadas de mulheres e, segundo ela, devolve aos espectadores a violência nelas acumulada, visto que de onde se vem e o que se viveu é difícil de ser narrado, mas ser ouvido é ainda pior (Prugnard, 2017).

Porque eu me entediei muito com o teatro, porque o teatro francês é uma coisa muito apaixonada pelo texto, o texto todo-poderoso, uma espécie de saliência da literatura, e eu me disse, não é mais possível, não, Brecht e Shakespeare não são meus contemporâneos, se eles estivessem vivos hoje escreveriam outras coisas sobre o nosso tempo, etc., e eu precisava, eu me aborrecia tanto no teatro, eu queria que isso pulsasse, queria que pulsasse, que as pessoas realmente ficassem viciadas. [...]. Na cena rock eu encontrei a energia que falta no teatro, porque na cena rock eles não ligam, tu podes parar de cantar, tomar uma cerveja, fumar um cigarro, te atirar na coisa, não importa, é algo flexível, e eu adoro a energia do rock porque é alguma coisa ainda, para mim, que está vinculada à tragédia grega, é dionisíaca ${ }^{26}$ (Prugnard, 2018).

Nesse tipo de proposição, escrita pela dramaturga e diretora, o textomaterial corresponde à natureza flexível da dramaturgia e da própria escritura teatral, que a todo momento se propõe à indefinição entre a escritura dramática e a escritura cênica, com a dramaturgia sendo um dispositivo proposto para produzir o jogo e promover os efeitos de sentido. Da dramaturgia, os textos residuais, materiais, guardarão os traços do processo.

Há um certo tempo a natureza textual da dramaturgia passou a ser refutada, talvez por isso se tornou frequente se ouvir "eu escrevi uma dramaturgia” e não mais "eu escrevi um texto", ainda que a materialidade do texto tenha permanecido,

\footnotetext{
25 “M.A.M.A.E. Assassinato - Artístico - Munição - Ação - Explosão. Visão geral dos ataques suicidas perpetrados por artistas”.

${ }^{26}$ Parce que je m'ai beaucoup ennuyé dans le théâtre, car le théâtre français, c'est quelque chose de très amoureux du texte, le texte tout puissant, une espèce de surplomb de la littérature, et je me suis dit, c'est plus possible, non, Brecht et Shakespeare ne son pas mes contemporains, s'ils seraient vivants aujourd'hui ils écriraient d'autres choses sur notre époque, etc., et j'avais besoin, je m'ennuyait tellement au théâtre, je voulait que ça pulse, je voulait que ça pulse, que les gens réellement soient accrochés. [...]. Dans la scène en rock j'ai trouvé l'énergie qui me manque au theâtre, parce que dans la scène au rock ils s'en fout, tu veux, tu peux arrêter de chanter, boire une bière, fumer une clope, se jeter dans le truc, c'est pas grave, en commence, c'est quelque chose de souple, et j'adore l'énergie du rock parce que c'est quelque chose là encore, pour moi, qui est reliée à la tragédie grecque, c'est dionysiaque. (Tradução nossa)
} 
como fantasma ou fetiche. "Eu articulei, propus tal dramaturgia" que conduziu à uma escritura teatral, produzindo tal texto ou dele se servindo, nos parece mais pertinente, ainda que faltem estudos que evidenciem de que modo, na escritura teatral, se reconhecem na encenação os aspectos visíveis da dramaturgia.

\section{Referências}

BOUDIER, Marion. "O Exemplo de Uma Dramaturgia Prospectiva e Documentária Para Ça ira (1) Fin de Louis, de Joël Pommerat”. Cena, Porto Alegre, p. 33-41, setdez, 2019.

BRAUN, Edward. El director y la escena: del naturalismo a Grotowski. Buenos Aires: Editorial Galerna, 1986.

CORNAGO, Óscar. "Individuo versus sociedad. En torno a Rodrigo García." In Cartografía teatral: Los escenarios de Cádiz en el Festival Iberoamericano de Teatro 2008. Ed. Grace Dávila, Polly J. Hodge y Claudia Villegas-Silva. Ediciones electrónicas de GESTOS, 2009. Disponível em: https://www.humanities.uci.edu/gestos/fit2008/content.html. Acesso em: 05 nov. 2020.

DANAN, Joseph. "A dramaturgia no tempo do pós-dramático". Cena, Porto Alegre, p. 14-23, set-dez, 2019.

DANAN, Joseph. Absence et presence du texte théâtral. Paris: Actes- Sud-Papiers, 2018.

DANAN, Joseph. Entre théâtre et performance. Paris: Actes Sud-Papiers, 2013.

DANAN, Joseph. "Fin de la dramaturgie?, in "Frictions no 10. Théâtres-écritures, automne-hiver, 2006, pp. 46-51.

DANAN, Joseph. "Mutações da dramaturgia". Moringa, vol. 1, n. 1, p. 117-123, janeiro, $2010 b$.

DANAN, Joseph. O que é a dramaturgia? Tradução de Luís Varela. Lisboa: Editora Licorne, 2010a.

DORT, Bernard. "L'état d'esprit dramaturgique", in Théâtre/Public, janvier, 1986.

DUPONT, Florence. Aristóteles ou o vampiro do teatro ocidental. Tradução de Joseane Prezotto, Marcelo Bourscheid, Rodrigo Tadeu Gonçalves, Roosevelt Rocha, Sergio Maciel. Desterro [Florianópolis]: Cultura e Barbárie, 2017. 
GAYOT, Joëlle \& POMMERAT, Joël. Joël Pommerat, troubles. Paris: Actes Sud, 2009. GOUHIER, Henri. Le Théâtre et les Arts à deux temps. Paris: Flammarion, 1989.

HORMIGÓN, Juan Antonio. "Lessing y el nascimento del dramaturgista" in, HORMIGÓN, Juan Antonio. La profesión del dramaturgista. (Org.) Madri: Asociación de Directores de Escena de España, 2011.

LEHMANN, Hans-Thies. Teatro pós-dramático. Tradução de Flora Süssekind. São Paulo: Cosac Naify, 2007.

MASSA, Clóvis Dias. "A questão da teatralidade na dramaturgia do espectador", in DESGRANGES, Flávio; SIMÕES, Giuliana (Orgs.). O ato do espectador. Perspectivas artísticas e pedagógicas. São Paulo-Florianópolis: Hucitec Editor, 2017. p. 53-74.

PAIS, Ana. O discurso da cumplicidade. Dramaturgias contemporâneas. Lisboa: Edições Colibri, 2004.

PAVIS, Patrice. Dicionário de teatro. Trad. J. Guinsburg, Maria Lúcia Pereira e outros. São Paulo: Editora Perspectiva, 1999.

PAVIS, Patrice. Dicionário da performance e do teatro contemporâneo. São Paulo: Perspectiva, 2017.

PROTAR, Camille. "Écritures plurielles, écritures scéniques. Rencontres du metteur en scène avec l'auteur", in PLUTA, Izabella (Org.) Metteur en scène aujourd'hui. Identité artistique en question? Rennes: Presses Universitaires de Rennes, 2017.

PRUGNARD, Nadège. Entrevista a Clóvis Dias Massa. La Chartreuse de Villeneuve lez Avignon - Centre national des écritures du spectacle, 04 de abril de 2018. Entrevista transcrita não publicada.

PRUGNARD, Nadège. M.A.M.A.E. \& autres textes. Marseille: Al Dante, 2017.

SARRAZAC, Jean-Pierre. Poética do drama moderno: de Ibsen à Koltès. Tradução de Newton Cunha. São Paulo: Perspectiva, 2017.

SERMON, Julie \& Chapuis, Yvane. Partition(s): Objet et conception des pratiques scéniques (20e et 21e siècles). Dijon: Les Presses du réel/La Manufacture, 2016.

STRANGER, Inés. "Rodrigo García: entre drame et performance", in SARRAZAC, Jean-Pierre \& NAUGRETTE, Catherine (Org.). La réinvention du drama (sous l’influence de la scène). Études Théâtrales, no 38-39, 2007, p. 173-176.

TACKELS, Bruno. Les écritures de plateau. Besançon: Les Solitaires Intempestifs, 2015. 
TACKELS, Bruno. Rodrigo García. Besançon: Les Solitaires Intempestives, 2007.

Recebido em: 14/12/2020

Aprovado em: 30/01/2021 